\title{
Survey of Dirofilaria immitis antigen and antibodies to Leishmania infantum and Toxoplasma gondii in cats from Madeira Island, Portugal
}

\author{
Michelle Neves ${ }^{1}$, Ana Patrícia Lopes ${ }^{2}$, Carolina Martins ${ }^{3}$, Raquel Fino ${ }^{3}$, Cláudia Paixão ${ }^{3}$, Liliana Damil ${ }^{3}$,
} Clara Lima ${ }^{4}$, Ana Margarida Alho ${ }^{5}$, Henk D. F. H. Schallig ${ }^{6}$, Jitender P. Dubey ${ }^{7}$ and Luís Cardoso ${ }^{2^{*}}$ (D)

\begin{abstract}
Background: Dirofilaria immitis, Leishmania infantum and Toxoplasma gondii are zoonotic parasites which can affect domestic cats. Considering the lack of published data from the local feline population, this study aimed to assess infection with or exposure to these pathogens in cats from Madeira Island, Portugal.

Methods: One hundred and forty-one domestic cats (77 males and 64 females; median age: 2 years) were sampled at a veterinary medical centre in Funchal, from September 2018 to January 2019. Serum samples were tested for $D$. immitis antigen, with an enzyme-linked immunosorbent assay kit, and for antibodies to Leishmania spp. or to T. gondii, with the direct agglutination test and the modified agglutination test, respectively.

Results: Five cats (3.5\%; $95 \%$ confidence interval, Cl: 1.2-8.1) were positive to D. immitis; no cats were seropositive to Leishmania spp. (0\%; 95\% Cl: 0-2.6\%); and 43 cats (30.5\%; 95\% Cl: 23.0-38.8\%) were seropositive to T. gondii. Prevalence of the $D$. immitis antigen was significantly different between cats that received ectoparasiticides and those which did not (0 vs 12.2\%; $P=0.009$ ). Prevalence of antibodies to T. gondii was significantly different between juvenile and adult cats (12.8 vs 38.0\%; $P=0.007)$. There were two cats concurrently positive to $D$. immitis and T. gondii, but no statistical association between these two dependent variables was found $(P=0.641)$.

Conclusions: To our knowledge, this is the first report of the presence of parasites D. immitis and T. gondii in the feline population of Madeira Island. Knowledge on the epidemiological situation of these and other zoonotic pathogens should raise awareness, both at the veterinary medical and public health levels, and contribute to promoting prevention and control.
\end{abstract}

Keywords: Agglutination tests, Enzyme-linked immunosorbent assay, Epidemiology, Europe, Feline, Serology, Vectorborne pathogens, Zoonotic

*Correspondence: Icardoso@utad.pt

${ }^{2}$ Department of Veterinary Sciences, and Animal and Veterinary Research

Centre (CECAV), UTAD, Vila Real, Portugal

Full list of author information is available at the end of the article

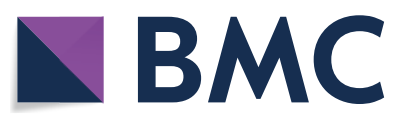

(c) The Author(s) 2020. This article is licensed under a Creative Commons Attribution 4.0 International License, which permits use, sharing, adaptation, distribution and reproduction in any medium or format, as long as you give appropriate credit to the original author(s) and the source, provide a link to the Creative Commons licence, and indicate if changes were made. The images or other third party material in this article are included in the article's Creative Commons licence, unless indicated otherwise in a credit line to the material. If material is not included in the article's Creative Commons licence and your intended use is not permitted by statutory regulation or exceeds the permitted use, you will need to obtain permission directly from the copyright holder. To view a copy of this licence, visit http://creativeco mmons.org/licenses/by/4.0/. The Creative Commons Public Domain Dedication waiver (http://creativecommons.org/publicdomain/ zero/1.0/) applies to the data made available in this article, unless otherwise stated in a credit line to the data. 


\section{Background}

The nematode Dirofilaria immitis and protozoans Leishmania infantum and Toxoplasma gondii are zoonotic parasites which can affect domestic cats [1]. Dirofilaria immitis has mosquitoes as vectors, primarily from genera Culex, Aedes or Anopheles, and may cause cardiopulmonary dirofilariasis or heartworm disease, a potentially fatal illness in cats [2]. Illness usually develops as the so-called heartworm-associated respiratory disease (HARD) syndrome, then resulting in pulmonary inflammation and thromboembolism, often leading to fatal acute lung injury [3]. Clinical signs associated with feline cardiopulmonary dirofilariasis include tachypnea, coughing and increased respiratory effort, anorexia, vomiting, diarrhoea and weight loss, and occasional neurologic manifestations $[4,5]$. Ascites, hydrothorax, chylothorax, pneumothorax, ataxia, seizures, and syncope have also been reported, but are not common [3]. Additionally, many cats have subclinical infections, i.e. without any detectable clinical signs, even knowing that only a small number of heartworms can compromise survival of their feline hosts [6, 7]. In humans, D. immitis might cause single or, more rarely, multiple pulmonary benign granulomas in peripheral areas occasionally misdiagnosed as malignant lesions $[2,8]$.

Leishmania infantum is transmitted mainly by phlebotomine sand flies among dogs, the primary reservoir of the protozoan parasite, but cats, humans and several other animals are also vertebrate hosts [9, 10]. Feline leishmaniosis caused by $L$. infantum predominantly manifests by distinct cutaneous lesions, although visceral and ocular involvement have also been reported [11, 12]. In Europe, human leishmaniosis is mainly observed in adults immunocompromised by HIV or immunosuppressants and in children $[13,14]$.

Toxoplasma gondii can infect almost all homeothermic animals as intermediate hosts, but domestic cats and other felids are the only definitive hosts of the parasite $[15,16]$. After primary infection, infected cats may excrete millions of oocysts in their faeces into the environment, thus playing an important role in the spread of T. gondii [17]. Infections in domestic and wild cats are generally subclinical, but severe disease may occur, with interstitial pneumonia identified as a potential cause of mortality. Clinical findings may include ocular, gastrointestinal, hepatic, pancreatic, pulmonary and neuromuscular manifestations [18-20]. In immunocompromised adult humans and congenitally infected children, toxoplasmosis may be the cause of high morbidity and mortality, but infection in immunocompetent people is mainly subclinical $[21,22]$.

Dirofilaria immitis, L. infantum and T. gondii are pathogens endemic in animal and human populations from many parts of the world, including southern Europe [1]. However, no published information is available from the feline population on the Madeira archipelago, the southernmost territorial part of Portugal. Considering this lack of epidemiological data, the present report aimed at assessing the prevalence of $D$. immitis antigen and also those of antibodies to L. infantum and T. gondii in cats from Madeira Island.

\section{Methods}

\section{Geographical area of the study}

This study was conducted on Madeira Island, the main island of Madeira archipelago (a Portuguese autonomous region), on the African plate in the Atlantic Ocean, southwest of mainland Portugal. The island has an area of $741 \mathrm{~km}^{2}$ (53.9 and $23 \mathrm{~km}$ maximum length and width, respectively) and around 262,500 inhabitants, 130,000 of which live in the capital city, Funchal, the main urban center and port, on the south coast. In addition to Funchal, there are nine other municipalites on Madeira Island: Calheta, Câmara de Lobos, Machico, Ponta do Sol, Porto Moniz, Ribeira Brava, Santa Cruz, Santana and São Vicente. In general, Madeira Island has a temperate Mediterranean climate on the north coast and a subtropical dry climate on the south coast, with the economy being largely tourism-oriented. The monthly average air temperature is higher during summer $\left(22.2^{\circ} \mathrm{C}\right.$ in August in Funchal) and lower in winter (15.9 ${ }^{\circ} \mathrm{C}$ in February in Funchal). Annual precipitation ranges from $553 \mathrm{~mm}$ in Funchal (58 m above sea level) to over $2000 \mathrm{~mm}$ in the north-facing slopes, increasing with altitude [23].

\section{Animals and samples}

A total of 141 domestic cats were sampled at the veterinary medical centre of Sociedade Protetora dos Animais Domésticos (SPAD; Society for the Protection of Domestic Animals), in Funchal, from September 2018 to January 2019. The cats were brought in mainly for routine observation, clinical consultation, medical treatment or neutering surgery, by their owners, guardians or legal keepers, who signed an informed consent for inclusion of the animals in the study. Data available on the municipality of origin, age, sex, breed, fur length, housing, clinical status (regarding manifestations compatible with cardiopulmonary dirofilariasis, leishmaniosis and toxoplasmosis) and use of ectoparasiticides and macrocyclic lactones were registered for each cat (Table 1). Clinical manifestations looked for were anaemia, anorexia, ascites, ataxia, chylothorax, coughing, cutaneous lesions, diarrhoea, dyspnoea, fever, hydrothorax, increased respiratory effort, jaundice, pale mucous membranes, pneumothorax, seizures, and syncope, tachypnea, vomit, and weight 
Table 1 Prevalence of Dirofilaria immitis antigen and antibodies to Toxoplasma gondii in cats from Madeira Island, Portugal, according to the categories of several independent variables

\begin{tabular}{|c|c|c|c|}
\hline Variable/category & No. (\%) of cats tested & Percentage ( $n$ ) of D. immitis-positive & $\begin{array}{l}\text { Percentage (n) of } \\
\text { T. gondii-positive }\end{array}$ \\
\hline Municipality & $141(100)$ & $P=0.654^{\mathrm{a}}$ & $P=0.459^{b}$ \\
\hline Funchal & $90(63.8)$ & $4.4(4)$ & $27.8(25)$ \\
\hline Other & $51(36.2)$ & $2.0(1)$ & $35.3(18)$ \\
\hline Age group & $139(98.6)$ & $P=0.322^{\mathrm{a}}$ & $P=0.007^{c}$ \\
\hline Juvenile [5-11 months] & $39(27.7)$ & $0(0)$ & $12.8(5)$ \\
\hline Adult [1-21 years] & $100(70.9)$ & $5.0(5)$ & $38.0(38)$ \\
\hline Sex & $141(100)$ & $P=1.0^{\mathrm{a}}$ & $P=0.067^{d}$ \\
\hline Female & $64(45.4)$ & $3.1(2)$ & $39.1(25)$ \\
\hline Male & $77(54.6)$ & $3.9(3)$ & $23.4(18)$ \\
\hline Breed & $141(100)$ & $P=1.0^{\mathrm{a}}$ & $P=0.247^{a}$ \\
\hline Mixed & $133(94.3)$ & $3.8(5)$ & $29.3(39)$ \\
\hline Defined $^{k}$ & $8(5.7)$ & $0(0)$ & $50.0(4)$ \\
\hline Fur length & $138(97.9)$ & $P=1.0^{\mathrm{a}}$ & $P=0.218^{e}$ \\
\hline Short & $101(71.6)$ & $3.0(3)$ & $27.7(28)$ \\
\hline Medium & $37(26.2)$ & $2.7(1)$ & $40.5(15)$ \\
\hline Housing & $138(97.9)$ & $P=1.0^{\mathrm{a}}$ & $P=0.081^{f}$ \\
\hline Indoors & $34(24.1)$ & $2.9(1)$ & $17.6(6)$ \\
\hline Outdoors or mixed & $104(73.8)$ & $3.8(4)$ & $35.6(37)$ \\
\hline Clinical status' & $141(100)$ & $P=0.134^{\mathrm{a}}$ & $P=0.705^{9}$ \\
\hline Non-suspect & $122(86.5)$ & $2.5(3)$ & $29.5(36)$ \\
\hline Suspect & $19(13.5)$ & $10.5(2)$ & $36.8(7)$ \\
\hline Ectoparasiticides $^{m}$ & $103(73.0)$ & $P=0.009^{a}$ & $P=0.147^{h}$ \\
\hline Yes & $62(44.0)$ & $0(0)$ & $25.8(16)$ \\
\hline No & $41(29.1)$ & $12.2(5)$ & $41.5(17)$ \\
\hline Macrocyclic lactones ${ }^{n}$ & $107(75.9)$ & $P=0.076^{\mathrm{a}}$ & $P=0.066^{i}$ \\
\hline Yes & $44(31.2)$ & $0(0)$ & $18.2(8)$ \\
\hline No & $63(44.7)$ & $7.9(5)$ & $36.5(23)$ \\
\hline Total & $141(100)$ & $3.5(5)$ & $30.5(43)$ \\
\hline
\end{tabular}

a Fisher's exact test

${ }^{\mathrm{b}} \mathrm{X}^{2}=0.549, d f=1$

c $x^{2}=7.189, d f=1$

${ }^{\mathrm{d}} x^{2}=3.351, d f=1$

${ }^{\mathrm{e}} x^{2}=1.520, d f=1$

${ }^{f} x^{2}=3.050, d f=1$

${ }^{9} x^{2}=0.143, d f=1$

${ }^{\mathrm{h}} \mathrm{x}^{2}=2.106, d f=1$

$x^{2}=3.384, d f=1$

j Calheta $(n=3 ; 2.1 \%)$, Câmara de Lobos ( $n=19 ; 13.5 \%)$, Ponta do Sol $(n=4 ; 2.8 \%)$, Porto Moniz $(n=1 ; 0.7 \%)$, Ribeira Brava $(n=4 ; 2.8 \%)$ and Santa Cruz $(n=20 ; 14.2 \%)$

k Persian $(n=1 ; 0.7 \%)$ and Siamese $(n=7 ; 5.0 \%)$

I Clinical manifestations compatible with cardiopulmonary dirofilariosis and/or toxoplasmosis, comprising: anaemia, anorexia, diarrhoea, dyspnoea, fever, jaundice, pale mucous membranes and vomit

$m$ Dinotefuran and pyriproxifen, fipronil and (S)-methoprene, fluralaner, lotilaner or spinosad

${ }^{n}$ Eprinomectin or milbemycin oxime

loss. Minimum and maximum ages were 5 months and 21 years, respectively (median: 2 years; interquartile range: 0.7-6.0 years). All the cats had been born on Madeira Island and had no travelling history to mainland Portugal or any other destination. Blood samples $(1 \mathrm{ml})$ were collected by jugular or cephalic venipuncture. Serum was separated by centrifugation and stored at $-20{ }^{\circ} \mathrm{C}$ until use. 


\section{Detection of $D$. immitis antigen}

Serum samples were tested for $D$. immitis antigen with a commercial enzyme-linked immunosorbent assay kit according to the manufacturer's instructions (PetChek Canine Heartworm Antigen Test ${ }^{\circledR}$, IDEXX Laboratories, Westbrook, Maine, USA). This test detects antigen from live adult female heartworms or dying male $(n \geq 5)$ and female heartworms [3, 24]. Following the manufacturer's instructions, a sample was considered qualitatively positive if it had more intense colour (blue) than the negative control; and all positive samples were retested for confirmation.

\section{Detection of antibodies to $L$. infantum}

The direct agglutination test (DAT) for titration of IgG antibodies specific to Leishmania spp. used a standard freeze-dried antigen at a concentration of $5 \times 10^{7}$ promastigotes per milliliter (Amsterdam University Medical Centres, Academic Medical Centre at the University of Amsterdam, Department of Medical Microbiology, Section Experimental Parasitology, Amsterdam, The Netherlands), following a predefined protocol [25]. Feline sera were diluted two-fold from 1:25 to 1:3200 in saline solution $(0.9 \% \mathrm{NaCl})$ containing $0.1 \mathrm{M} \beta$-mercapto-ethanol, with a cut-off titre of 100 chosen for seropositivity [26]. Results obtained with DAT are expressed as an antibody titre, i.e. the reciprocal of the highest dilution at which agglutination (large diffuse blue mats) is still clearly visible after $18 \mathrm{~h}$ incubation at room temperature [25].

\section{Detection of antibodies to $T$. gondii}

Sera were also tested for IgG antibodies to $T$. gondii at two-fold dilutions from 1:20 to 1:640 with a modified agglutination test (MAT) commercial kit (Toxo-Screen $\mathrm{DA}^{\circledR}$, bioMérieux, Lyon, France) according to the manufacturer's instructions. Positive and negative control samples, supplied with the kit, were included in each plate. Results obtained with the MAT were expressed as an antibody titre, i.e. the reciprocal of the highest dilution at which agglutination (at least one half of the well's diameter) was still visible after $18 \mathrm{~h}$ incubation at room temperature. A cut-off titre of $20(2 \mathrm{IU} / \mathrm{ml}$ in relation to a World Health Organization international reference serum) was chosen to maximize both sensitivity and specificity of the test $[27,28]$.

\section{Data analysis}

Exact binomial 95\% confidence intervals (CI) were established for prevalence values. The chi-square test and Fisher's exact test (FET) were used to compare proportions of positivity among categories of the same independent variables and also total prevalence values of each agent. A $P$ value $\leq 0.05$ was considered as statistically significant.
Analyses were performed with Stemstat, IBM SPSS Statistics $26^{\circledR}$ software and WinEpi. Assuming a default 50\% prevalence value and a $95 \%$ confidence level, a convenience sample of 141 cats corresponds to an absolute error of $8.25 \%[29,30]$.

\section{Results}

Five cats (3.5\%; 95\% CI: $1.2-8.1 \%)$ were found positive to $D$. immitis antigen (with all positive results confirmed by retesting); they were aged 2 years $(n=2), 5$ years $(n=1)$, 6 years $(n=1)$ and 10 years-old $(n=1)$. Prevalence of $D$. immitis antigen was significantly different between cats that received ectoparasiticides and those which did not $(0$ vs $12.2 \%$, respectively; $P=0.009$; Table 1 ).

No cats were seropositive to Leishmania spp. (0\%).

Forty-three cats (30.5\%; 95\% CI: $23.0-38.8 \%$ ) were seropositive to $T$. gondii, with MAT titres of 20 in five, 40 in six, 80 in one and $\geq 640$ in 31 cats. Thus, most seropositive cats $(31 / 43 ; 72.1 \%)$ had a high titre $(\geq 640)$. The 43 cats seropositive to T. gondii were aged from 6 months to 21 years-old. Prevalence of antibodies to $T$. gondii was significantly different between juvenile (5-11 monthsold) and adult cats (1-21 years-old; 12.8 vs $38.0 \%$, respectively; $P=0.007$; Table 1 ).

Two cats were simultaneously positive to $D$. immitis and T. gondii, but no statistical association between these two dependent variables was found (FET: $P=0.641$ ). Moreover, no statistically significant differences were found between the categories of the independent variables municipality, sex, breed, fur length, housing, clinical status and macrocyclic lactones, both for $D$. immitis and T. gondii (Table 1).

\section{Discussion}

To the best of our knowledge, this is the first study describing the prevalence of infection with or exposure to vector-borne and zoonotic pathogens in the feline population from Madeira Island. The number of cats together with the incorporation of different animals may be considered a representative sample of Madeira Island, thus allowing an extrapolation of results to the regional feline population. No significant differences were found for the municipality, sex, breed, fur length, housing, clinical status and macrocyclic lactones (Table 1), suggesting that both $D$. immitis and T. gondii are uniformly distributed among the surveyed feline population of Madeira.

A few epidemiological studies have been performed in dogs from this region on D. immitis $[8,31]$ and L. infantum [31], but there were no published data regarding cats. Madeira is the region of Portugal with the highest prevalence of heartworm infection in dogs, in which cardiopulmonary dirofilariosis is the major endemic vector-borne disease [8,31]. Although 
positivity could be expected among the feline population in a location where cardiopulmonary dirofilariasis is endemic in the canine population, this study documents $D$. immitis infection in cats on Madeira for the first time.

The $3.5 \%$ prevalence of $D$. immitis antigen in cats in the present study is significantly different from that of a recent report in $\operatorname{dogs}\left(40.0 \% ; \chi^{2}=4.705, d f=1, P<\right.$ 0.0001) [31]. Cats are susceptible hosts, but they seem to be more resistant than dogs to infection with adult $D$. immitis [3]. According to another recent report [5], a theoretical prevalence of $9-18 \%$ of the infection prevalence in dogs is expected to be observed in cats. This assumption would suggest the prevalence of heartworm antigen in cats on Madeira to be 3.6-7.2\%, which is in agreement with the value found in the regional feline population. Antigenaemia, mainly from adult female heartworms [32], is detectable in cats from around 5.5 to 8 months after natural infection [3]. Thus, six 5-month-old cats (data not shown) were not expected to be antigen-positive, a circumstance which increases the estimate of $D$. immitis antigen prevalence from $3.5 \%(5 / 141)$ to $3.7 \%$ $(5 / 136)$.

Tests for detection of heartworm circulating antigens strongly depend on the number of mature adult females present in the host and cats usually have a much lower prevalence of adult infections than dogs [4]. A positive antigen detection test result is indicative of active adult infection, but a negative result does not rule out that the animal can be infected with only male, pre-adult or very old adult worms $[5,33]$. Nevertheless, $D$. immitis antigen tests of the current generation identify most infections consisting of at least one mature female heartworm and are nearly $100 \%$ specific [3]. On the other hand, presence of antibodies to $D$. immitis may only indicate exposure to heartworm larvae rather than necessarily an active or persistent infection [4]. Tests for the detection of $D$. immitis antibodies detect infection earlier, but may also result in more false positives; $D$. immitis antigen tests detect infection later, but a positive result is generally confirmatory [3].

Transmission of heartworm is dependent upon several factors, including a suitable climate to support a viable mosquito population and the extrinsic incubation of D. immitis within those intermediate hosts [34]. The presence of $D$. immitis larvae in Culex theileri suggests that this mosquito species is actively involved as a natural vector of heartworm on Madeira [35]. An analysis of data from five meteorological stations in Portugal (years 2003-2013), revealed Madeira Island to be the region registering the highest number of days with suitable conditions for $D$. immitis transmission (average of 209.9 days per year) [36].
All the $D$. immitis antigen-positive cats $(n=5)$ did not receive ectoparasiticides. The products listed in Table 1 do not have a repellent or anti-feeding effect protecting against infective mosquito bites, but they are insecticides that contribute to reduce the total number or abundance of insects. Even if it could have been not regular, the application of ectoparasiticides was associated with a lower prevalence of infection in cats that received those products $(P=0.009$; Table 1$)$. In addition, none of the $D$. immitis-positive cats received macrocyclic lactones, but comparison with animals treated with them revealed a statistically non-significant difference, yet close to significance $(P=0.079$; Table 1$)$. Many cats may have received macrocyclic lactones not specifically for the prevention of D. immitis, but as a therapy against other endoparasites and even ectoparasites. Anyway, prevention of heartworm infection is attainable in cats by the routine administration of macrocyclic lactones, including eprinomectin and milbemycin oxime [37, 38]. Monthly chemoprophylaxis is a safe and effective option for cats living in geographical areas where $D$. immitis infection is considered endemic and exposure to infectious mosquitoes is likely [3].

The zero prevalence of antibodies to Leishmania spp. in cats from Madeira Island is in line with the value $(0 \%)$ found in 10 apparently healthy dogs also from Madeira assessed, from October 2010 to April 2011, for L. infantum antibodies with a rapid test [31]. Some dogs living on Madeira were detected as seropositive to Leishmania spp. with the DAT, but those animals were born or had been in mainland Portugal (L. Cardoso, unpublished data), where zoonotic leishmaniosis caused by $L$. infantum is endemic [31, 39]. Specimens of Phlebotomus sergenti and Sergentomyia minuta have been found in Funchal, on Madeira Island [40], and on another island of the archipelago [41], respectively. The former species has been proven as vector of Leishmania aethiopica and Leishmania tropica [42], but its role as vector of $L$. infantum has never been confirmed [43]. The role of $S$. minuta in Leishmania spp. transmission among mammal hosts still needs to be elucidated [42]. Cases of canine leishmaniosis caused by L. tropica have been diagnosed in Morocco, in Africa, which is the continental country geographically closest to Madeira Island [44].

The $30.5 \%$ prevalence of antibodies to T. gondii found in the present study differs significantly $\left(\chi^{2}=2.154\right.$, $d f=1, P=0.031)$ from the $20.5 \%$ found in domestic cats from the Lisbon metropolitan area, in mainland Portugal, using the same serological test [45]. This situation may due to the fact that different cut-offs have been used, i.e. a titre of 20 in the present study and a titre of 40 by the other authors [45]. Notwithstanding, the climacteric characteristics of Madeira might also mean more 
favourable conditions to the sporulation of $T$. gondii oocysts $[16,36]$. On the other hand, a higher prevalence of $T$. gondii antibodies in adult (aged 1-21 years) in comparison with juvenile cats (5-11 months-old; Table 1) may be due to the fact that increasingly older cats have more chances to eat infected tissues or to contact with the surrounding environment potentially contaminated with oocysts [16]. Seropositive cats are likely to have already excreted $T$. gondii oocysts, whereby serological surveys for the detection of antibodies can help to determine the potential risk of infection in defined geographical areas $[46,47]$. There are currently no data available on the seroprevalence of $T$. gondii from the canine population of Madeira.

\section{Conclusions}

The present study provides evidence that cats on Madeira Island are at risk of becoming infected with $D$. immitis and T. gondii. On the other hand, no cats were found seropositive to Leishmania spp. Surveying these zoonotic parasites in the feline population of Madeira supplements their epidemiological mapping in cats from Portugal and Europe. In the scope of clinical practice, cardiopulmonary dirofilariasis and toxoplasmosis should be included in the differential diagnosis of feline patients with clinical signs compatible with both parasitoses.

\section{Abbreviations \\ Cl: confidence interval; DAT: direct agglutination test; FET: Fisher's exact test; MAT: modified agglutination test.}

\section{Acknowledgements}

Publication of this paper has been sponsored by Bayer Animal Health in the framework of the 15th CVBD World Forum Symposium.

\section{Authors' contributions}

MN conceiving the study, conducted clinical examination, sample collection and testing for D. immitis, and helped drafting the manuscript. APL conducted testing for T. gondii and data analysis, and revised the manuscript. CM, RF, CP and LD conducted clinical examination and sample collection. CL and AMA contributed with data analysis and revised the manuscript. HDFHS contributed with testing for $L$. infantum and revised the manuscript. JPD contributed with data analysis and revised the manuscript. LC supervised the study, conducted testing for $L$. infantum and data analysis, and drafted the manuscript. All authors read and approved the final manuscript.

\section{Funding}

This study was supported by project UIDB/CVT/00772/2020 funded by Fundação para a Ciência e a Tecnologia (FCT).

\section{Availability of data and materials}

Data supporting the conclusions of this article are included within the article and its additional file. The datasets used and/or analysed during the present study are available from the corresponding author on reasonable request.

\section{Ethics approval and consent to participate}

All clinical procedures complied with the Portuguese legislation for the protection of animals used for scientific purposes (i.e. Decree-Law no. 113/2013, of 7 August 2013), which transposes European legislation (i.e. Directive
2010/63/EU of the European Parliament and of the Council, of 22 September 2010).

\section{Consent for publication}

Not applicable.

\section{Competing interests}

The authors declare that they have no competing interests.

\section{Author details}

1 University of Trás-os-Montes e Alto Douro (UTAD), Vila Real, Portugal.

${ }^{2}$ Department of Veterinary Sciences, and Animal and Veterinary Research Centre (CECAV), UTAD, Vila Real, Portugal. ${ }^{3}$ Sociedade Protetora dos Animais Domésticos (SPAD), Funchal, Portugal. ${ }^{4}$ Department of Biological Sciences, Faculty of Pharmacy, Universidade do Porto, Oporto, Portugal. ${ }^{5}$ CIISA, Faculty of Veterinary Medicine, University of Lisbon, Lisboa, Portugal. ${ }^{6}$ Department of Medical Microbiology, Experimental Parasitology Section, Amsterdam University Medical Centres, Academic Medical Centre at the University of Amsterdam, Amsterdam, The Netherlands. ${ }^{7}$ Animal Parasitic Diseases Laboratory, Beltsville Agricultural Research Center, Agricultural Research Service, US Department of Agriculture, Beltsville, MD, United States of America.

Received: 16 December 2019 Accepted: 24 February 2020

Published online: 21 April 2020

\section{References}

1. Baneth G, Thamsborg SM, Otranto D, Guillot J, Blaga R, Deplazes P, et al. Major Parasitic zoonoses associated with dogs and cats in Europe. J Comp Pathol. 2016;155(Suppl. 1):S54-74.

2. Simón F, Siles-Lucas M, Morchón R, González-Miguel J, Mellado I, Carretón $\mathrm{H}$, et al. Human and animal dirofilariasis: the emergence of a zoonotic mosaic. Clin Microbiol Rev. 2012;25:507-44.

3. American Heartworm Society. Current feline guidelines for the prevention, diagnosis, and management of heartworm (Dirofilaria immitis) infection in cats. Wilmington: Am Heartw Soc; 2014.

4. McCall JW, Genchi C, Kramer LH, Guerrero J, Venco L. Heartworm disease in animals and humans. Adv Parasitol. 2008;66:193-285.

5. Venco L, Genchi M, Genchi C, Gatti D, Kramer L. Can heartworm prevalence in dogs be used as provisional data for assessing the prevalence of the infection in cats? Vet Parasitol. 2011;176:300-3.

6. Dillon R. Clinical significance of feline heartworm disease. Vet Clin North Am Small Anim Pract. 1998:28:1547-65.

7. Atkins CE, DeFrancesco TC, Coats JR, Sidley JA, Keene BW. Heartworm infection in cats: 50 cases (1985-1997). J Am Vet Med Assoc. 2000;217:355-8.

8. Araujo AM. Canine and human Dirofilaria immitis infections in Portugal. A review. Parassitologia. 1996;38(Suppl. 1-2):366.

9. Quinnell RJ, Courtenay O. Transmission, reservoir hosts and control of zoonotic visceral leishmaniasis. Parasitology. 2009;136:1915-34.

10. Solano-Gallego L, Miró G, Koutinas A, Cardoso L, Pennisi MG, Ferrer L, et al. LeishVet guidelines for the practical management of canine leishmaniosis. Parasit Vectors. 2011;4:86.

11. Pennisi MG, Cardoso L, Baneth G, Bourdeau P, Koutinas A, Miró G, et al. LeishVet update and recommendations on feline leishmaniosis. Parasit Vectors. 2015:8:302.

12. Pimenta P, Alves-Pimenta S, Barros J, Barbosa P, Rodrigues A, Pereira MJ, et al. Feline leishmaniosis in Portugal: 3 cases (year 2014). Vet Parasitol Reg Stud Rep. 2015;1-2:65-9.

13. Dujardin JC, Campino L, Cañavate C, Dedet JP, Gradoni L, Soteriadou $\mathrm{K}$, et al. Spread of vector-borne diseases and neglect of leishmaniasis, Europe. Emerg Infect Dis. 2008;14:1013-8.

14. Horrillo L, Castro A, Matía B, Molina L, García-Martínez J, Jaqueti J, et al. Clinical aspects of visceral leishmaniasis caused by L. infantum in adults. Ten years of experience of the largest outbreak in Europe: what have we learned? Parasit Vectors. 2019;12:359.

15. Dubey JP. Toxoplasmosis of animals and humans. 2nd ed. Boca Raton: CRC Press; 2010. 
16. Lopes AP, Dubey JP, Dardé ML, Cardoso L. Epidemiological review of Toxoplasma gondii infection in humans and animals in Portugal. Parasitology. 2014;141:1699-708.

17. Dubey JP. Tissue cyst tropism in Toxoplasma gondii: a comparison of tissue cyst formation in organs of cats, and rodents fed oocysts. Parasitology. 1997;115:15-20.

18. Dubey JP, Carpenter JL. Histologically confirmed clinical toxoplasmosis in cats: 100 cases (1952-1990). J Am Vet Med Assoc. 1993;203:1556-66.

19. Hawkins EC, Davidson MG, Meuten DJ, Rottman JB, Kennedy-Stoskopf S Levy JK, et al. Cytologic identification of Toxoplasma gondii in bronchoalveolar lavage fluid of experimentally infected cats. J Am Vet Med Assoc. 1997;210:648-50.

20. Davidson MG. Toxoplasmosis. Vet Clin North Am Small Anim Pract. 2000;30:1051-62.

21. Belanger F, Derouin F, Grangeot-Keros L, Meyer L. Incidence and risk factors of toxoplasmosis in a cohort of human immunodeficiency virusinfected patients: 1988-1995. HEMOCO and SEROCO Study Groups. Clin Infect Dis. 1999;28:575-81.

22. Avelino MM, Campos D, Carmo Barbosa Parada J, Castro AM, Medical School of the Federal University of Goiás, Institute of Tropical Pathology and Public Health of the Federal University of Goiás, et al. Pregnancy as a risk factor for acute toxoplasmosis seroconversion. Eur J Obstet Gynecol Reprod Biol. 2003;108:19-24.

23. Official Madeira Tourism Board. Madeira \& Climate. In: Madeira Islands. Direção Regional do Turismo. http://www.visitmadeira.pt/en-gb/madeira. Accessed 8 Dec 2019

24. Maia C, Ramos C, Coimbra M, Cardoso L, Campino L. Prevalence of Dirofilaria immitis antigen and antibodies to Leishmania infantum in cats from southern Portugal. Parasitol Int. 2015;64:154-6.

25. Schallig HD, Schoone GJ, Beijer EGM, Kroon CC, Hommers M, Özbel $Y$, et al. Development of a fast agglutination screening test (FAST) for the detection of anti-Leishmania antibodies in dogs. Vet Parasitol. 2002;109:1-8.

26. Cardoso L, Lopes AP, Sherry K, Schallig H, Solano-Gallego L. Low seroprevalence of Leishmania infantum infection in cats from northern Portugal based on DAT and ELISA. Vet Parasitol. 2010;174:37-42.

27. Dubey JP, Lappin MR, Thulliez P. Long term antibody responses of cats fed Toxoplasma gondii tissue cysts. J Parasitol. 1995:81:887-93.

28. Lopes AP, Cardoso L, Rodrigues M. Serological survey of Toxoplasma gondii infection in domestic cats from northeastern Portugal. Vet Parasitol. 2008;155:184-9.

29. Petrie A, Watson P. Statistics for veterinary and animal science. 3rd ed. Chichester: Wiley-Blackwell; 2013.

30. Thrusfield M, Christley R, Brown H, Diggle PJ, French N, Hoew K, et al. Veterinary epidemiology. 4th ed. Hoboken: Wiley Blackwell; 2018.

31. Cardoso L, Mendão C, Madeira de Carvalho L. Prevalence of Dirofilaria immitis, Ehrlichia canis, Borrelia burgdorferi sensu lato, Anaplasma spp and Leishmania infantum in apparently healthy and CVBD-suspect dogs in Portugal —a national serological study. Parasit Vectors. 2012;5:62.

32. Snyder PS, Levy JK, Salute ME, Gorman SP, Kubilis PS, Smail PW, et al. Performance of serologic tests used to detect heartworm infection in cats. J Am Vet Med Assoc. 2000;216:693-700.
33. Berdoulay P, Levy JK, Snyder PS, Pegelow MJ, Hooks JL, Tavares LM, et al. Comparison of serological tests for the detection of natural heartworm infection in cats. J Am Anim Hosp Assoc. 2004:40:376-84.

34. Genchi C, Rinaldi L, Mortarino M, Genchi M, Cringoli G. Climate and Dirofilaria infection in Europe. Vet Parasitol. 2009;163:286-92.

35. Santa-Ana M, Khadem M, Capela R. Natural Infection of Culex theileri (Diptera: Culicidae) with Dirofilaria immitis (Nematoda: Filarioidea) on Madeira Island, Portugal. J Med Entomol. 2006;43:104-6.

36. Alho AM, Nunes T, Rinaldi L, Meireles J, Belo S, Deplazes P, et al. Transmission risk of Dirofilariosis in Portugal. Parasit Vectors. 2014;7(Suppl. 1):016.

37. Baker CF, Tielemans E, Pollmeier MG, McCall JW, McCall SD, Irwin J, et al. Efficacy of a single dose of a novel topical combination product containing eprinomectin to prevent heartworm infection in cats. Vet Parasitol. 2014;202:49-53.

38. Little SE, Hostetler JA, Thomas JE, Bailey KL, Barrett AW, Gruntmeir K, et al. Moxidectin steady state prior to inoculation protects cats from subsequent, repeated infection with Dirofilaria immitis. Parasit Vectors. 2015;8:107.

39. Cortes S, Vaz Y, Neves R, Maia C, Cardoso L, Campino L. Risk factors for canine leishmaniasis in an endemic Mediterranean region. Vet Parasitol. 2012;189:189-96.

40. Alves-Pires C, Capela RA. Phlébotomes du Portugal. VIII. Premiére mention de Phlebotomus (Paraphlebotomus) sergenti Parrot, 1917 à l'île de Madère. Parasite. 1917;1996(3):94.

41. Alves-Pires C, Capela RA, Pena I. Os Flebótomos de Portugal. IX. Presença de Sergentomyia minuta (Rond., 1843) na Selvagem Grande (Madeira). Bol Soc Port Entomol. 1843;1997(178):389-95.

42. Maroli M, Feliciangeli MD, Bichaud L, Charrel RN, Gradoni L. Phlebotomine sandflies and the spreading of leishmaniases and other diseases of public health concern. Med Vet Entomol. 2013;27:123-47.

43. Ready PD. Biology of phlebotomine sand flies as vectors of disease agents. Ann Rev Entomol. 2013;58:227-50.

44. Guessous-Idrissi N, Berrag B, Riyad M, Sahibi H, Bichichi M, Rhalem A. Leishmania tropica: etiologic agent of a case of canine visceral leishmaniasis in northern Morocco. Am J Trop Med Hyg. 1997;57:172-3.

45. Esteves F, Aguiar D, Rosado J, Costa ML, de Sousa B, Antunes F, et al. Toxoplasma gondii prevalence in cats from Lisbon and in pigs from centre and south of Portugal. Vet Parasitol. 2014;200:8-12.

46. Lucas SR, Hagiwara MK, Loureiro VS, Ikesaki JY, Birgel EH. Toxoplasma gondii infection in Brazilian domestic outpatient cats. Rev Inst Med Trop Sao Paulo. 1999;41:221-4.

47. Miró G, Montoya A, Jiménez S, Frisuelos C, Mateo M, Fuentes I. Prevalence of antibodies to Toxoplasma gondii and intestinal parasites in stray: farm and household cats in Spain. Vet Parasitol. 2004;126:249-55.

\section{Publisher's Note}

Springer Nature remains neutral with regard to jurisdictional claims in published maps and institutional affiliations.

Ready to submit your research? Choose BMC and benefit from

- fast, convenient online submission

- thorough peer review by experienced researchers in your field

- rapid publication on acceptance

- support for research data, including large and complex data types

- gold Open Access which fosters wider collaboration and increased citations

- maximum visibility for your research: over $100 \mathrm{M}$ website views per year

At BMC, research is always in progress.

Learn more biomedcentral.com/submissions 